\title{
Balanced Scorecard Implementation at Rang Dong Plastic Joint-Stock Company (RDP)
}

\author{
Luu Trong Tuan \\ National University of Ho Chi Minh City, Vietnam \\ E-mail: luutrongtuan@hcm.fpt.vn \\ Sundar Venkatesh \\ Asian Institute of Technology (AIT), Thailand
}

\begin{abstract}
From the balanced scorecard (BSC) framework, which encourages the use of both financial and non-financial measures of performance, allowing the firm to pinpoint its strategic objectives via balancing four perspectives financial, customers, internal business processes, and learning and growth - to measure firm performance (Kaplan and Norton, 1992; Kaplan and Norton, 1996b), the paper sought to explore how balanced business scorecards were designed and to what extent of success they were implemented at Rang Dong Plastic Joint-Stock Company (RDP) in terms of its organizational structure and company philosophy.
\end{abstract}

Keywords: Balanced scorecard, Performance measurement

\section{Introduction}

Performance measurement systems aim to "integrate organizational activities across various managerial levels and functions" (McNair et al., 1989). The need for integration is supported by Hronec, who defines a performance measurement system as a "tool for balancing multiple measures (cost, quality, and time) across multiple levels (organization, processes and people)" (Hronec, 1993).

Edson (1988) and Talley (1991) highlight the need for performance measurement systems to focus attention on continuous improvement. Green et al. (1991) suggest that performance measurement systems should "target the value-added activities of the company". Kaplan (1991) states that an effective performance measurement system "should provide timely, accurate feedback on the efficiency and effectiveness of operations".

Recent research has demonstrated that conspicuous links between a firm's approach to strategic planning and its business performance exist in small as well as in large organizations (Lyles et. al, 1993; Jennings \& Beaver, 1997; Juul Andersen, 2000; Ernst \& Young, 2000). A common tool utilized to support strategic management activity in large firms is the Balanced Scorecard.

\section{The Balanced Scorecard (BSC) Framework}

The BSC provides a framework, which encourages the use of both financial and non-financial measures of performance, allowing the firm to pinpoint its strategic objectives via balancing four perspectives - financial, customers, internal business processes, and learning and growth - to measure firm performance (Kaplan and Norton, 1992; Kaplan and Norton, 1996b). The effectiveness of the balanced scorecard is based on its capability to translate a firm's mission and strategy into a comprehensive set of performance measures (Kaplan and Norton, 2001).

The balanced scorecard approach involves identifying the key components of operations, setting goals for them, and then exploring ways to measure progress toward achieving those goals. Taken together, the measures provide a holistic view of what is happening both inside and outside the firm or operational level, thus allowing each constituent of the firm to see how their activities contribute to attainment of the firm's overall mission.

The framework is based on the premise that those properties of the financial accounting system such as conservatism, transaction emphasis, and dollar base unit of measurement, hinder it from measuring the key activities of the company adequately. Rather, Kaplan and Norton (1992) suggest supplementing the traditional financial measurement system with non-financial measures of customer relations, internal business processes, and firm learning growth in order to specify what the firm expects to receive from and give to the various stakeholder groups in exchange for those groups' continued contribution toward the firm's pursuit of its objectives. Figure 1 illustrated by Kaplan and Norton (1996b) identifies relationships and premises of the BSC. 
Within the BSC framework, four categories of measures are identified in order to achieve balance between the financial and the non-financial, between internal and external and between current performance and future performance (Kaplan and Norton, 1992). The four perspectives: financial, customer, processes, and learning and growth (as represented in Figure 1), - represent the views of four essential stakeholders in any business.

An example is displayed below (Figure 2) of the type of measures associated with each of these pillars used by Chemical Bank when it adopted the BSC to communicate and implement a new retail strategy in the face of declining margins and increasing competition (Kaplan and Klein, 1996: 1)

The balanced scorecard allows managers to look at the business from four important perspectives. It provides the answer to four basic questions (see Figure 3):

- How do customers see us? Customer Perspective

- What must we excel at? Internal Perspective

- Can we continue to improve and create value? Innovation and Learning Perspective

- How do we look to shareholders? Financial Perspective

Indicators included in a BSC can be either lagging or leading indicators. Outcomes are lagging indicators that show what has been accomplished. Usually, outcome indicators are generic measures, meaning that indicators are common for most companies. Leading indicators are the drivers of performance, which are unique for a particular firm. The driver is the cause and the outcome is the effect. All but the financial perspective perspectives in the BSC should include outcomes and drivers. The financial perspective only includes outcome indicators. "Ultimately, causal paths form all the measures on a Scorecard should be linked to financial objective" (emphasis in the original, Kaplan \& Norton, 1996a).

The BSC is cited by the Harvard Business Review as one of the 15 most important management concepts to have been introduced via articles. Since its introduction in 1992, the BSC has featured in a wealth of academic and practitioner papers; however, writing on the BSC focuses on its application in large organizations, drawing on case examples such as Mobil and CIGNA (Kaplan \& Norton, 1996b), ABB, Skandia, SKF and Halifax (Olve et al., 1999) - all multi billion Dollar companies. One explanation for this predominantly large company focus may be found in the challenges of communication, coordination, and control in large organizations. The task specialization and levels of organizational hierarchy that is required to support the scale of the organization make all forms of change more difficult in large organizations (Atkins \& Lowe, 1997). In Andersen's (2001) view, the fact that no comprehensive literature on the BSC used by SMEs exists today should not be taken as an indication that the BSC implementation is only appropriate for large organizations.

The remainder of this paper reports on Rang Dong Plastic Joint-Stock Company' attempts to devise a balanced scorecard from the author's suggestion to Mr. Ho Duc Lam, chairman of its board of directors. The following section will starts with a brief overview of the organizational context prior to presenting an analysis of the process whereby the scorecard was generated.

\section{Case Study: Rang Dong Plastic Joint-Stock Company (RDP)}

Company profile. Rang Dong Plastic Joint-Stock Company, (abbreviated to RDP), was established under the original name of UFEOC (Union Francaise d' Extreâme d'Orient des Caoutchouc) in 1962 in District 11, Saigon, Vietnam. From the early days, RDP has experienced rapid growth, and by 2009, the company's nation-wide operations generated annual sales amounting to over five hundred billion Vietnam dong (approximately thirty million US dollars).

Over the five year period from 2005 turnover has grown by just over 55 per cent, i.e. an average annual growth rate of over 11 per cent.

Financial information of Rang Dong Plastic Joint-Stock Company over the last five years is summarized in Table 1.

RDP is engaged in the development, production and distribution of household and engineering plastic products and has become a major player in this industry. Products and technologies emphasized and developed by RDP have set the standards in many key areas. Examples include performance standards for multi-layer flexible film packaging, which have been developed by RDP in co-operation with technological institutes and universities, as well as major innovations in the fields of EVA films and sheets, PU synthetic leather, and PE rigid sheets \& boards. 
From its location in district 11, Saigon, the firm has developed a sales and distribution network throughout Vietnam. Both products and technical know-how are readily available on a national scale, based on a network of local sales, service and customer advisory centres. Company operations include production facilities in District 11, $\mathrm{Cu}$ Chi district, Hoc Mon district (Saigon) and Binh Duong province in the south of Vietnam, as well as Khanh Hoa province for the North and Central markets.

Besides its head office, RDP has three other operational sites, Hanoi branch, Nghe An branch and Nha Trang branch (see Figure 4).

Organizational structure. According to Daft (1992) "an organization structure identifies the grouping together of individuals into departments and the grouping of departments into the total organization", and it "designates formal reporting relationships" and also "includes the design of systems to ensure effective communication, co-ordination, and integration of effort across departments".

In that sense, a firm's structure provides the infrastructure on which we can fine-tune an appropriate balanced business scorecard.

For RDP, a formal organization chart, displaying the company structure, does not exist. Formal relationships and groupings have developed historically with the company's growth over the years, allowing for change whenever necessary. However, it might be very useful in this context to capture some basic ideas of RDP's structure.

Applying the above definition by Daft (1992), RDP's structure may best be classified as a "hybrid structure". It combines an activity grouping of functional areas such as research and development, production, logistics, general administration including purchasing, finance and accounting, and the like, on the one hand, and a product-based or "output grouping", focusing on sales - which is structured around product divisions - on the other hand. For all areas except sales, this form of concentration brings with it the advantage of high efficiency. The sales activities, however, which are considered to be of major importance for the success of the whole company, are structured to meet the overarching goal of customer satisfaction first and foremost. The use of separate sales divisions for the product lines allows the company to focus on the specific needs of certain customer groups. The same is true for affiliated companies, which may be regarded as externalized sales departments for special product lines, serving special customer segments.

In order to gain close contact with customers, a regional structure has been chosen within product divisions, responsible for the engagement of sales representatives. Based on regional sales offices throughout Vietnam, regional markets can be served effectively.

It should be emphasized again that there is no formal or even fixed organization structure and the above represents a summary based on observation of what is generally happening within RDP.

Company philosophy. RDP's philosophy, as explicitly stated in the company's long-term plan, is directed towards delighting the customer. RDP's vision is expressed in the company's motto "Innovation, competence and performance" and it is a widely held view within the company that the above motto forms the cornerstone of the company's success. Underpinning this motto is a strong belief that quality, growth, profitability, valuing employees and a decentralized organization deliver the vision.

RDP defines innovation as "being one step ahead of the norm". Thus, the company builds on the capability of its employees in research and development, applies technology and continually assures its customers of the quality of its products and services. R\&D managers are active in technical associations and committees for the creation of new standards within the plastic packaging industry. Thus, managers keep themselves up to date with the latest developments and they also recognize the challenges facing tomorrow's markets. RDP's capability to innovate is also founded on research laboratories equipped with the latest technology.

RDP's competence shows itself in the company's capability to find individual solutions to its customers' specific demands and its wide range of back-up services. Competence is primarily developed through an ongoing staff-training programme in all technical areas and further supplemented through extensive dialogue and partnership arrangements with universities and technical institutions.

Performance is considered to be the third building block of RDP's success. Performance draws on a company infrastructure equipped to deal with customers' requests, as well as on highly qualified, trained and motivated employees. Supporting these two main platforms is a network of associations, co-operatives and various contact points with specialist institutions. 


\section{Scorecard design and implementation}

Kaplan and Norton (1992) envisaged that the identification of key performance measures would form a pre-requisite to developing the scorecard, and an iterative process would take place before the scorecard emerged.

In the case of RDP, a six-step methodology was adopted, based on the method established by Vitale et al. (1994) (see Figure 5).

It was evident that good communication and building of commitment was of the utmost importance. It was also obvious that the unique culture and existing company philosophy had to be incorporated into the scorecard for it to be acceptable to managers. Closely aligned to this was a need to link performance measures with company strategy.

In the case of RDP, senior management had traditionally been heavily involved in setting goals for individual divisions and project groups. Experience within the company had shown that appropriately set and defined targets contributed both to motivation of employees and the eventual success of the company. This culture was incorporated into the scorecard design. The perceived cornerstones of its success - innovation, competence and performance were incorporated into the scorecard. Managers, both senior and junior, viewed these three cornerstones as determinants of success and firmly believed that profitability, growth and quality would result from implementing this motto (Figure 6).

This model provides a strategic framework and indicates the elements of major importance for achieving overall corporate goals. Core to the philosophy at RDP is the strong communication which exists between the external customers, marketing, manufacturing and R\&D. Throughout the whole firm, the view was strongly held that innovation, competence and performance would result from continually focusing on this tripartite relationship. This relationship is illustrated in Figure 7.

By concentrating on the aspects of the business which created value for customers and, by thoroughly re-appraising the company philosophy and incorporating this into the performance measurement system, RDP was able to build a balanced business scorecard which acts as an effective means of communicating the strategy of the company throughout the whole organization.

The final scorecard which emerged from applying Vitale et al.'s (1994) six-step methodology (shown in Figure 5 ) is as shown in Figure 8.

\section{Concluding remarks}

Kaplan and Norton provide a very useful generic model in the form of their balanced business scorecard. As seen in this case study, the culture within the firm has to be of prime consideration in the construction of every case.

Visual presentation of the model is crucial, as most employees will relate to a visual presentation far more readily than to text or tables or other forms of presentation.

From this case study, a number of key issues can be distilled for the balanced scorecard to be successful in delivering strategic goals. The balanced business scorecard should:

- deliver information which is the spine of the strategy;

- function as the cornerstone of both the organization's current and future success by balancing short-term, essentially financial performance, with long-term growth opportunities;

- $\quad$ balance internal and external perspectives by ensuring that comparison against current competitors is undertaken, in addition to comparison with the organization's own past performance;

- $\quad$ highlight performance by adopting a broad perspective: financial, business processes, customer/market interfaces and employee motivation;

- $\quad$ act as an integrating tool, both horizontally (across functionality) and vertically (through levels of management), by communicating the business strategy and the organization's priorities;

- $\quad$ serve as a dynamic, continuous process used to evaluate performance and redefine strategy and measures based on results.

Using the BSC as a measurement system allows all strategic business units and work groups to focus on the critical drivers of future success for them. This in turn contributes to the achievement of overall corporate objectives. Linking the scorecard to key management processes, such as budgeting and business planning, ensures all energies are directed toward the fulfillment of strategies. Finally, cascading the scorecard to all levels 
of the company signals to every one of the 814 employees what constitutes success at RDP, and allows them to determine how their day-to-day actions contribute to that success. In his book, Ricardo Semler, CEO of Brazil's Semco corporation, argues: "No one can expect the spirit of involvement and partnership to flourish without an abundance of information available even to the most humble employee." The scorecard can be a key tool in the overall information-sharing strategy.

\section{References}

Andersen, H. (2001). Balanced Scorecard implementation in SMEs: Reflection on literature and practice. Paper presented to $4^{\text {th }}$ SME-SME International Conference, Allborg University, Denmark, 14-16 May 2001.

Atkins, M.H., \& Lowe, J.F. (1997). Sizing up the small firm: UK and Australian experience. International Small Business Journal, 15(3), 42-55.

Ban cong bo thong tin (RDP's corporate information release) (retrieved on 5 March 2008 [Online] Available:http://www1.bsc.com.vn:8080/EDMS/BscIpo.nsf/bf231f2bea0192394725713d002a2a5a/284957ae64d db73d4725713d002a5241/\$FILE/RDC_Announcement.pdf)

Daft, R.L. (1992). Organization Theory and Design. St. Paul West Publishing Company.

Edson, N.W. (1988). Performance measurement: key to world class manufacturing. APICS 31st Annual Conference Proceedings. APICS, Falls Church, VA, pp. 629-32.

Ernst \& Young. (2000). Research shows 35\% of investors' decisions are driven by non-financial performance, News Room, [Online] Available: http://www.ey.com/global/gcr.nsf/UK/press_release_measures_that_matter, (downloaded 28.1.2001).

Green, F.B., Amenkhienan, F., and Johnson, G. (1991). Performance measures and JIT. Management Accounting, Vol. LXXII, No. 8, February, pp. 50-3.

Hronec, S.M. (1993). Vital Signs: Using Quality, Time and Cost Performance Measurements to Chart Your Company's Future. New York, NY: Amacom.

Jennings, P., and Beaver, G. (1997). The performance and competitive advantage of small firms: a management perspective. International Small Business Journal, 15, 2, 63-75.

Juul Andersen, T. (2000). Strategic planning, autonomous actions anc corporate performance. Long Range Planning, 33, pp. 184-200.

Kaplan, R.S. (1991). New systems for measurement and control. The Engineering Economist, Vol. 36, No. 3, Spring, pp. 201-18.

Kaplan, R.S., \& Norton, D.P. (1996a). Linking the balanced scorecard to strategy. California Management Review, 39(1), 53-79.

Kaplan, R.S., and Klein, N. (1996). Chemical bank: Implementing the Balanced Scorecard. Case Studies from Havard Business School: Implementing the Balanced Scorecard: Havard Business School Publishing.

Kaplan, R.S., and Norton, D.P. (1992). The balanced scorecard - measures that drive performance. Harvard Business Review, Vol. 70, January-February, pp.71-9.

Kaplan, R.S., and Norton, D.P. (1996b). Using the balanced scorecard as a strategic management system. Harvard Business Review, Vol. 74, January-February, pp.75-79.

Kaplan, R.S., and Norton, D.P. (2001). The strategy focused organization: How the Balanced Scorecard companies thrive in the new business environment. Boston, Massachusetts: Harvard Business School Press.

Lyles, M.A, Baird, I.S., Orris, J.B., and Kurato, D.F. (1993). Formalized planning in small business: Increasing strategic success. Journal of Small Business Management, 31, 2, pp. 38-51.

McNair, C.J., Mosconi, W., and Norris, T.F. (1989). Beyond the Bottom Line - Measuring World Class Performance. Homewood, IL: Business One Irwin.

Olve, N., Roy, J., and Wetter, M. (1999). English translation, $1^{\text {st }}$ published in Swedish 1997). Performance drivers: A practical guide to using the Balanced Scorecard. UK: Wiley.

Talley, D.J. (1991). Total Quality Management - Performance and Cost Measures: The Strategy for Economic Survival. ASQC Quality Press, Milwaukee, WI.

Vitale, M., Mavrinac, S.C., and Hauser, M. (1994). New process/financial scorecard: a strategic performance measurement system. Planning Review, Vol. 22, pp.12-6. 
Table 1. Rang Dong Plastic Joint-Stock Company, financial record

\begin{tabular}{|c|c|c|c|c|c|}
\hline VND’000,000s & 2009 & 2008 & 2007 & 2006 & 2005 \\
\hline Turnover & 506,200 & 448,500 & 421,400 & 370,500 & 325,800 \\
EBIT $^{\mathrm{a}}$ & 13,600 & 11,900 & 9,080 & 8,250 & 6,480 \\
Number of employees & 814 & 748 & 702 & 1,038 & 1,025 \\
\hline
\end{tabular}

${ }^{\mathrm{a}} \mathrm{EBIT}$ is the Earnings Before Interest and Taxes.

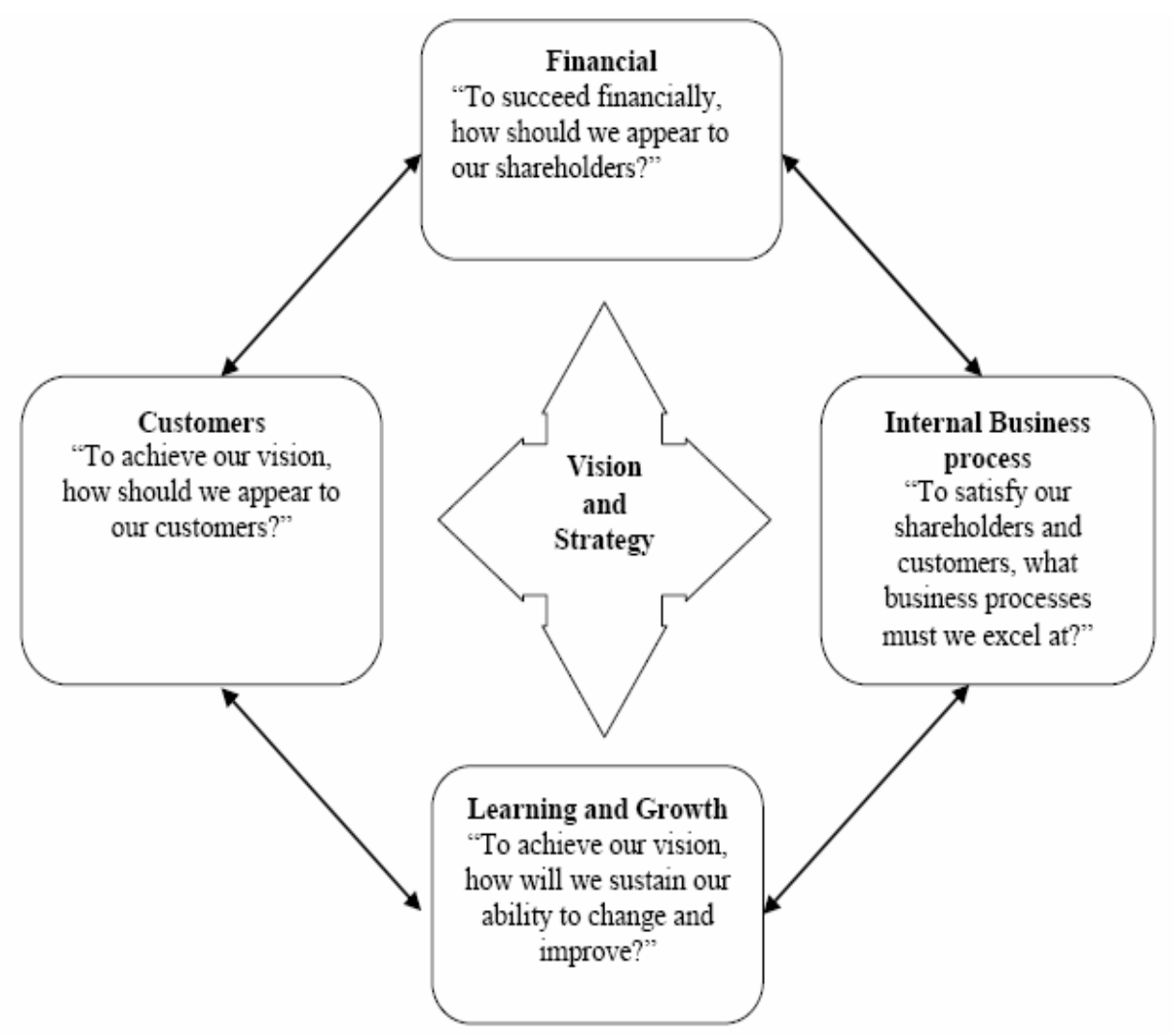

Figure 1. The balanced scorecard framework 


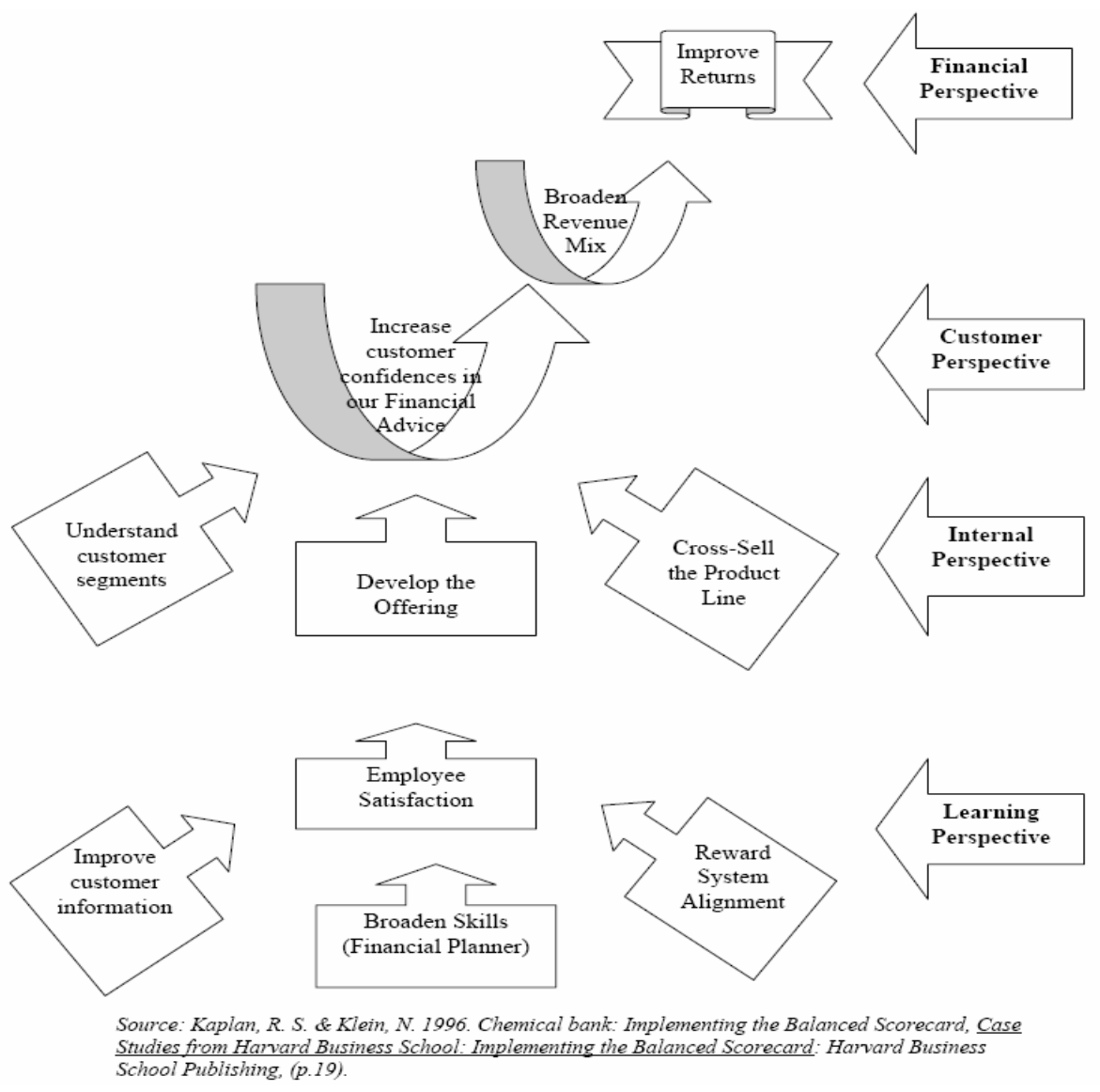

Figure 2. Types of measures associated with each BSC pillar

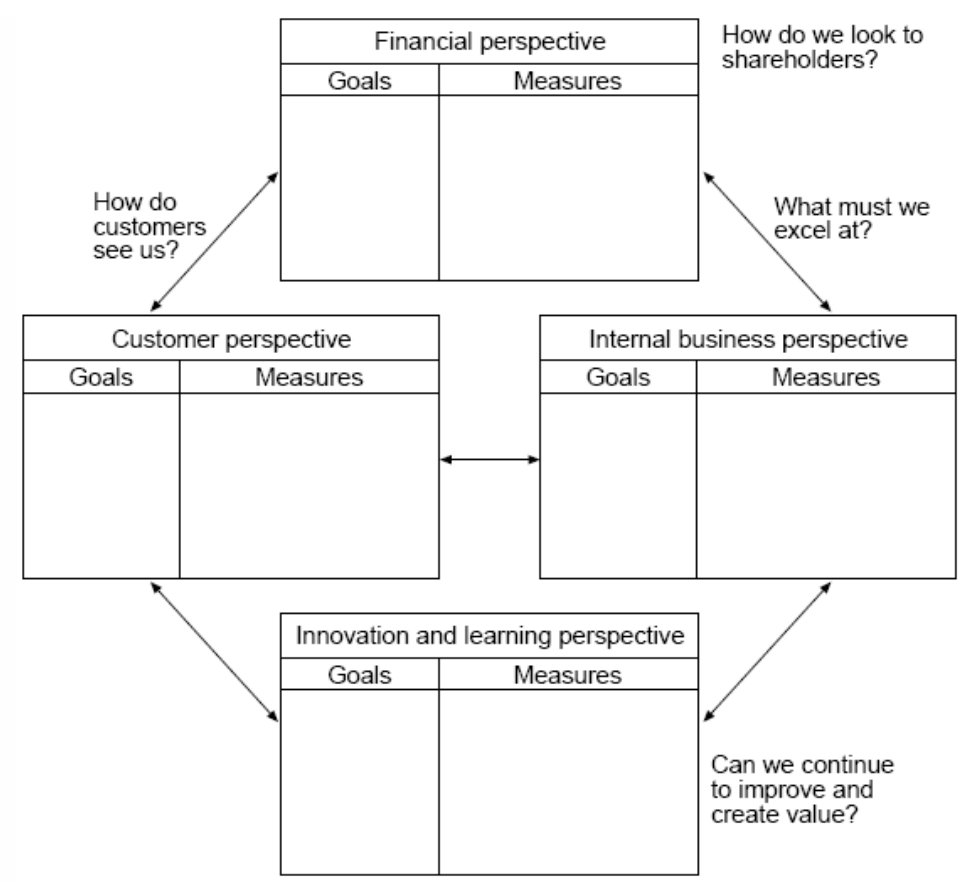

Figure 3. Different segments of the balanced scorecard 


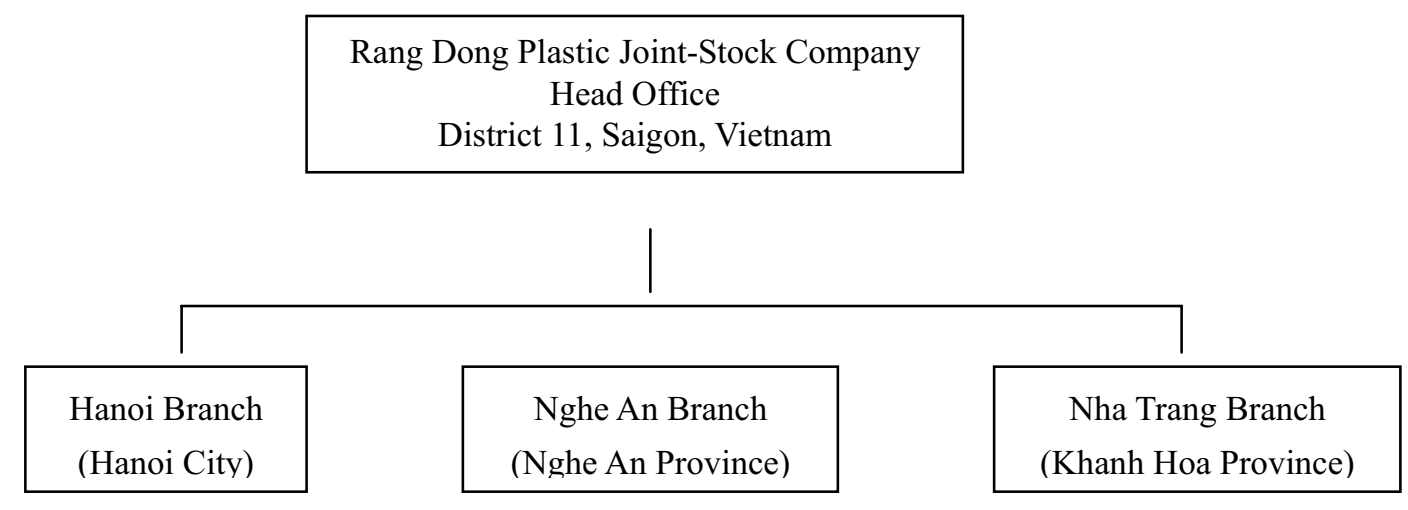

Figure 4. Regional organization of Rang Dong Plastic Joint-Stock Company

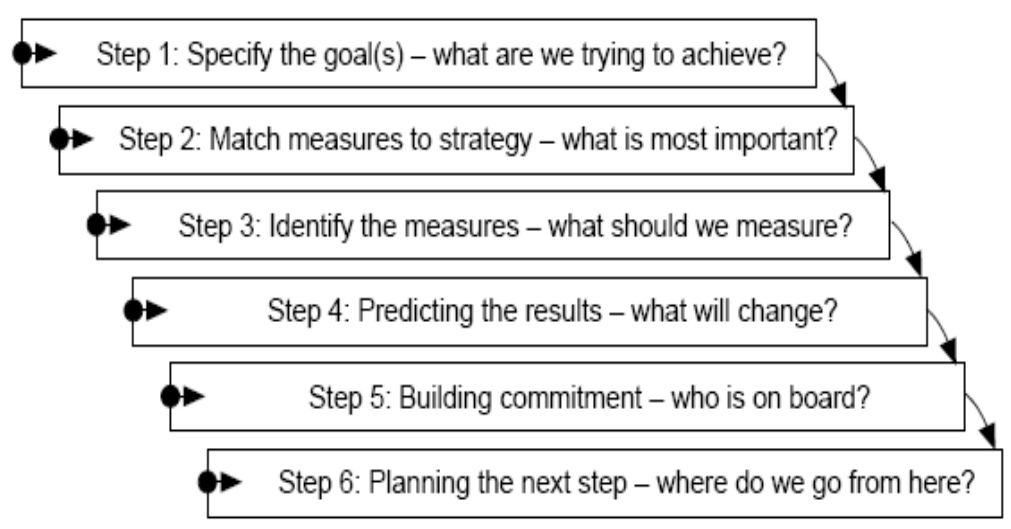

Figure 5. Six-step methodology 


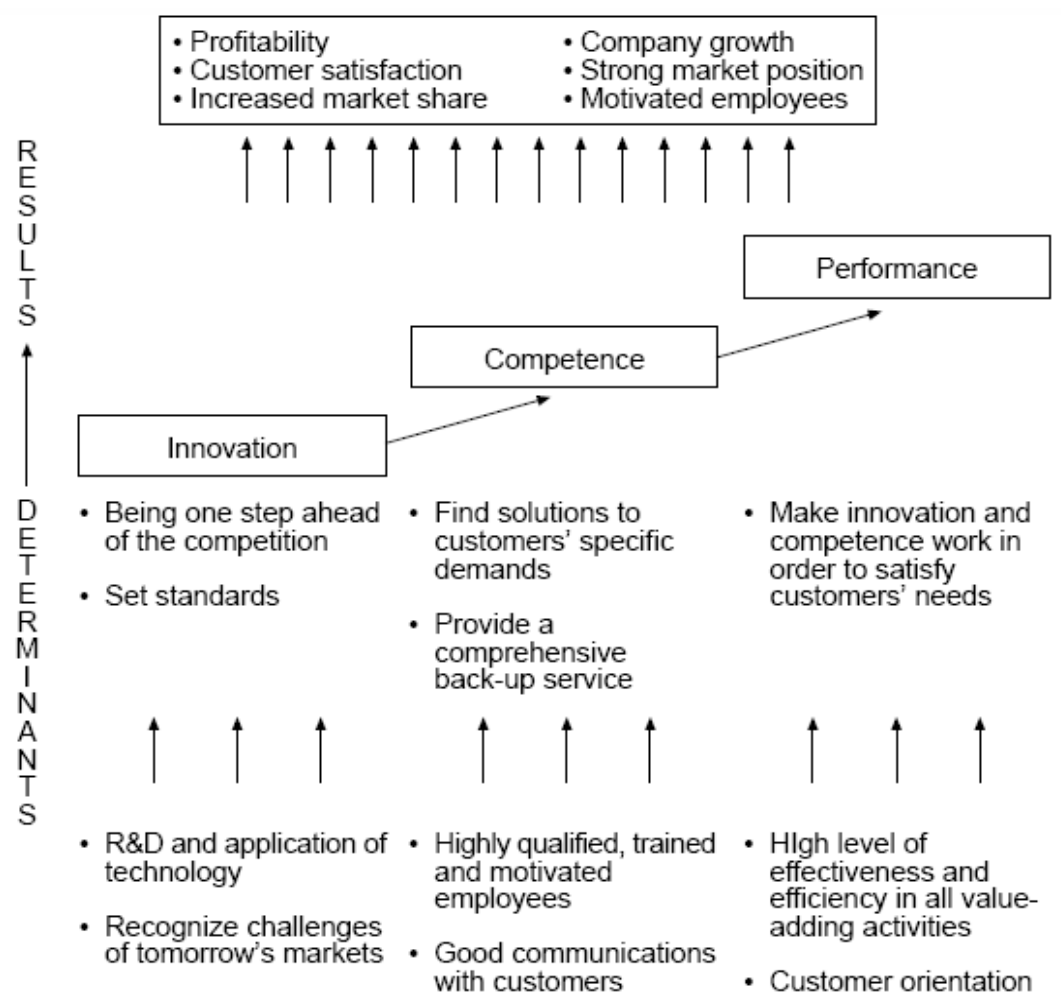

Figure 6. Corporate success determinants and results

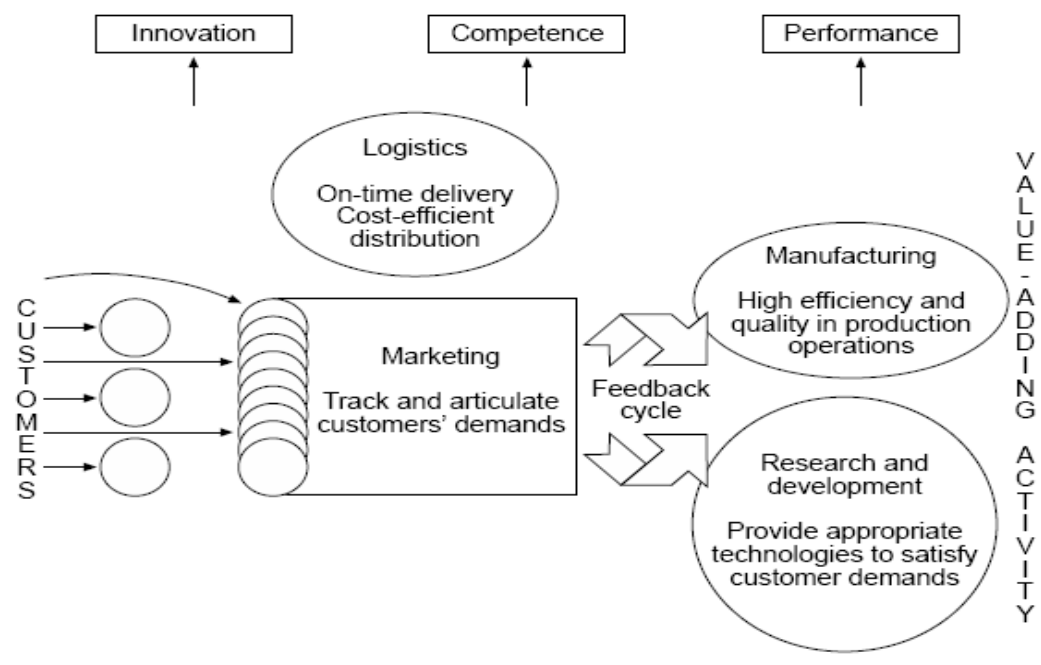

Figure 7. Creating value for the customer 


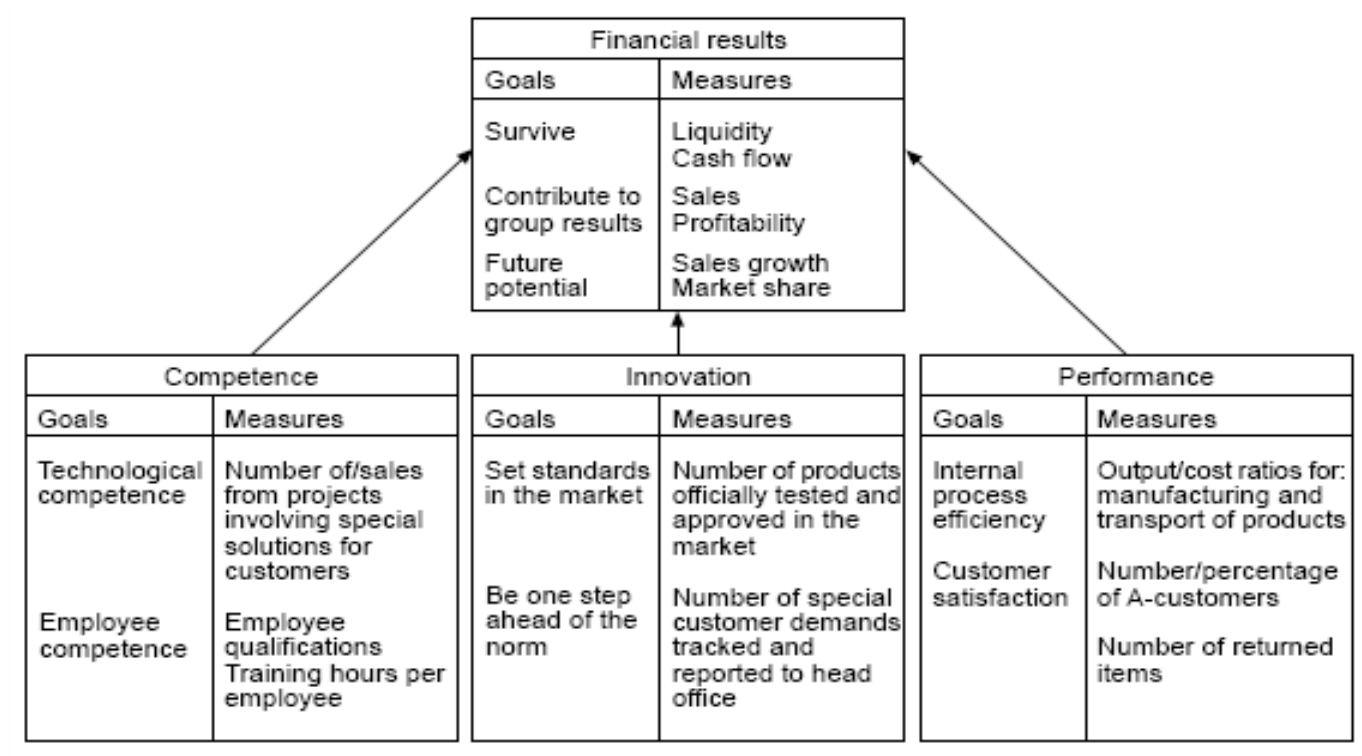

Figure 8. Business scorecard for RDP 